Como citar: de Alvarenga Filho, J., Anselmé, C., Sanglard, H., \& Lombardi, I. (2021). Carta ao nosso tempo: Covid19, políticas públicas e corpos em risco. PSI UNISC, 5(2), 9-19. doi: 10.17058/psiunisc.v5i2.16468

\title{
Carta a nossa época: Covid-19, políticas públicas e corpos em risco
}

\author{
Carta a nuestro tiempo: Covid-19, políticas públicas y organismos en riesgo \\ Letter to our time: Covid-19, public policies and bodies at risk
}

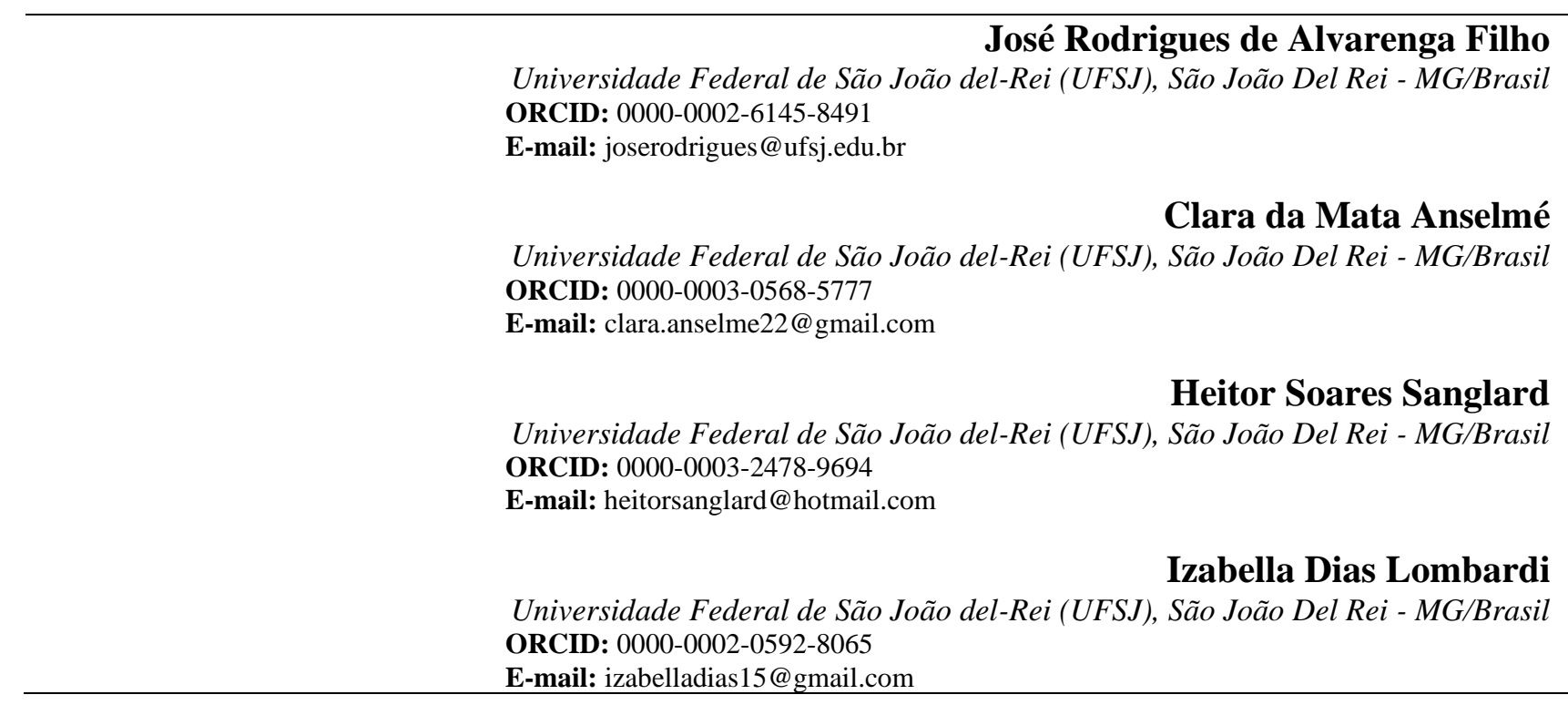

\begin{abstract}
Resumo
Nosso ensaio, escrito como uma carta direcionada a nossa época, tem por objetivo levantar algumas interrogações sobre o tema das políticas públicas em meio a pandemia de covid-19. Problematizamos se o maior perigo de nosso tempo é a doença que tira a vida de milhares e nos confina em casa, produzindo inseguranças sobre o viver coletivo, ou nossos estilos de vida destruidores da natureza. Para o desenvolvimento de nossa narrativa, política e metodologicamente composta como uma carta-manifesto, nos apoiamos na obra de diferentes autores e experimentamos a escrita coletiva, mesmo à distância, como uma forma de habitar as dores e as instabilidades de nosso existir confinado. Apontamos, ao final, nossa aposta nas políticas públicas enquanto potencializadoras de estratégias e práticas coletivas de resistência em meio à intensificação da agenda neoliberal e os riscos advindos da pandemia enquanto acontecimento político-sanitário. Por fim, pensamos na resistência enquanto àquilo que, em meio às capturas do capital, escapa por entre os dedos dos controles feito o correr da água entre as pedras.
\end{abstract}

Palavras-chaves: Políticas públicas; COVID-19; Pandemia; Neoliberalismo; Resistência.

\section{Resumen}

Nuestro ensayo, escrito como carta dirigida a nuestro tiempo, tiene como objetivo plantear algunas interrogantes sobre el tema de las políticas públicas en medio de la pandemia del covid-19. Nos preguntamos si el mayor peligro de nuestro tiempo es la enfermedad que se cobra la vida de miles de personas y nos confina en casa, produciendo inseguridades sobre la vida colectiva o nuestros estilos de vida destructores de la naturaleza. Para desarrollar nuestra narrativa, compuesta política y metodológicamente como un manifiesto-carta, nos apoyamos en el trabajo de diferentes autores y experimentamos con la escritura colectiva, incluso a distancia, como una forma de habitar los dolores e inestabilidades de nuestra confinada existencia. Al final, señalamos nuestra apuesta por las políticas públicas como potencializadores de estrategias y prácticas colectivas de resistencia en medio de la intensificación de la agenda neoliberal y los riesgos derivados de la pandemia como evento político-sanitario. Finalmente, pensamos en la resistencia como aquella que, en medio de las capturas de capitales, se escapa por los dedos de los controles como el fluir del agua entre piedras. 
Palabras clave: Políticas públicas; COVID-19; Pandemia; Neoliberalismo; Resistencia.

\begin{abstract}
Our essay, written as a letter addressed to our times, aims to raise some questions about the theme of public policies in the midst of the covid-19 pandemic. We question whether the greatest danger of our time is the disease that takes the lives of thousands and confines us at home, producing insecurities about collective living, or our nature-destroying lifestyles. To develop our narrative, politically and methodologically composed as a manifesto-letter, we rely on the work of different authors
\end{abstract}

and experiment with collective writing, even at a distance, as a way to inhabit the pains and instabilities of our confined existence. In the end, we point out our bet on public policies as potentializers of strategies and collective practices of resistance amid the intensification of the neoliberal agenda and the risks arising from the pandemic as a political-sanitary event. Finally, we think of resistance as that which, amid the captures of capital, escapes through the fingers of controls like the flow of water between stones.

Keywords: Public policies; COVID-19; Pandemic; Neoliberalism; Resistance.

\section{O principal perigo}

Cara companheira,

Escrevemos esta carta porque sabemos que você, como nós, está à flor da pele diante da situação político-social-sanitária brasileira. Escrevemos na esperança de compartilhar interrogações e, principalmente, partilhar modos de olhar o mundo que nos tragam, apesar destes tempos tristes, alguma esperança atrevida, utopia ativa para continuarmos caminhando. Continuarmos sonhando, sem dúvida.

Nós lembramos que durante 21 anos uma geração inteira teve seus sonhos abortados e seus corpos subalternizados pela ditadura civil-militar brasileira. Centenas foram torturados e assassinados em nome do suposto combate aos "subversivos". Aqueles que sempre aplaudiram os horrores desse período sombrio de nossa recente história, hoje estão no poder. Por isso, cara companheira, é preciso, mais do que nunca, que estejamos atentos e fortes frente às ameaças que se avolumam diante de nós.

Apesar de não fazer tanto tempo que a nossa frágil democracia se fez presente, após o período de exceção militar, ouvimos, num misto de horror e tristeza, vozes que se levantam a clamar por novas intervenções militares, um novo Ato Institucional número 5. Contraditoriamente, as mesmas vozes que falam em liberdade individual - a liberdade neoliberal - são aquelas que ora clamam por ditadura. Todavia, sabemos que a contradição é apenas aparente e que a disputa política se dá em diferentes planos, inclusive no das narrativas. As rédeas de tal momento estão sendo conduzidas por ecos conservadoristas, negacionistas, que espalham fake news como arma narrativa, conturbando e confundindo ainda mais as pessoas diante de um contexto de incerteza e insegurança.

Se a situação política do país está conflituosa e tensa, não menos terrível está o contexto sanitário. Escrevemos esta carta em meio a notificação de mais de 300 mil mortos por Covid- $19^{1}$ no Brasil. Acreditamos que, infelizmente, quando esta carta chegar em suas mãos, os números já serão outros. O país tornou-se o principal epicentro da crise sanitária-política. Escrevemos enquanto o ar parece ter se tornado cada vez mais escasso e as resistências duvidosas. Como resistir? Como produzir potência, majorar a vida, em meios ao caos? Como fortalecer as políticas públicas em meio ao desmonte neoliberal que, no paradigma do "capitalismo de desastres" (Klein, 2008), aproveita-se das tragédias para intensificar os interesses do capital? Ou, simplesmente, como não sucumbir diante do vírus, dos fascismos e dos afetos de tristeza que atravessam nossos corpos?

O perigo da pandemia é aquilo que, à primeira vista, emerge como mais atual e

\footnotetext{
${ }^{1}$ No momento da primeira revisão do texto, chegamos a 519 mil mortos pela Covid-19.
} 
presente em nossas vidas hoje. A Covid-19 tem determinado a forma como experimentamos os espaços públicos, como trabalhamos remotamente e até os modos como sonhamos. Neste momento, companheira, as leituras e os estudos têm nos fortalecido. Buscamos ir ao encontro de autores e autoras que, para além dos diagnósticos tristes da realidade, nos ensejem linhas de esperança e potência.

Neste sentido, nos encontros com Mbembe (2020) e Krenak (2020a, 2020b), somos instigados a questionar se a pandemia é, de fato, o principal perigo que enfrentamos. Recordamos Foucault (1985, p. 256), velho amigo, quando este aponta que: "a escolha ético-política que devemos fazer a cada dia é determinar qual é o principal perigo". O principal perigo é o vírus ou o nosso modo coletivo de viver? Modo este que, segundo Preciado (2018, p. 11), produz "névoas tóxicas" no planeta. As toxinas são fabricadas diariamente e nos falam de um mundo hiperconectado, competitivo, racista, patriarcal, colonial. Sobretudo, de um sistema socioeconômico que explora e destrói os modos singulares de viver, a cultura e a tradição dos povos originários. Que, enfim, solapa a natureza. Esta, como questionou Galeano (2012, p. 40), se “fosse um banco já teria sido salva $^{2}$.

Krenak, em suas recentes obras (2019, 2020a, 2020b), não apenas faz duras críticas à sociedade branca eurocêntrica, como apresenta olhares diferentes sobre os sentidos da vida. A partir de seu prisma e de nosso contato com o seu pensamento, aprendemos que não há separação entre humano e natureza. Tudo e todos são natureza. O Rio Doce, exemplo caro a Krenak e aos povos indígenas, é um ser vivo que, como tal, tem seus cursos do viver, seus modos de existir.

\footnotetext{
${ }^{2} \mathrm{Na}$ crise dos bancos privados em 2008, nos Estados Unidos, o governo do país injetou bilhões de dólares para salvar os bancos da falência. A intervenção estatal foi comemorada mesmo por aqueles que defendiam abertamente a agenda neoliberal e o papel não intervencionista do Estado na economia.
}

A natureza é destruída em detrimento do capital e muitos de nós parecem ter se tornado cegos para enxergar tal violência. Em seu "ensaio sobre a cegueira humana", Saramago (1995) nos fala de uma cidade tomada por uma estranha epidemia de cegueira. Uma cegueira branca que não é originada por ausência de luz, mas por seu excesso. Padecemos por excesso: de luzes, de informações, de conexões, de pensamentos, de violências, de toxinas. Como pontua Krenak (2020, p. 4), "essa dor talvez ajude as pessoas a responder se somos de fato uma humanidade" ou um amontoado de gente que quanto mais vê, menos enxerga, quanto mais ouve, menos escuta, quanto mais se reúne, menos se encontra? Quanto mais corre, imersos numa pressa desenfreada, menos estamos presentes.

Seguimos automatizados, anestesiados demais para perceber a destruição ao nosso redor. Para Han (2017), padecemos por nossa submissão aos imperativos da autoperformance, da auto-produtividade. Nossa sociedade, pela ótica do autor, se constitui como um tempo em que o cansaço se torna esgotamento. Ou seja, somos atravessados por uma falta de energia para viver. Nessa dinâmica político-social, já não se trataria do corpo dócil descrito por Foucault (2014), na década de 1970. Não é mais por docilidade que o sistema capitalista atual nos coopta e controla, mas por sedução. No "capitalismo artista", descrito por Lipovetsky e Serroy (2015), mais eficiente do que a coerção, é a sedução; o convite para que todos, na era do individualismo exacerbado, da estetização capitalista do viver, criem suas vidas como obra de arte investindo no consumo de práticas para tornar-se mais belos, mais produtivos, mais eficientes, mais "resilientes".

Estamos diante de um mundo feito de fronteiras, de lógicas abissais (Santos, 2007), de divisas, de normas, de regras de exceção, em que já padecíamos de falta de ar antes da Covid- 
19. Milhares já viviam confinados antes do imperativo do isolamento social e seus corpos, submetidos a lógicas violentas, sobreviviam em meio aos riscos. Este sistema- capitalista, disciplinar, burguês, colonial - é uma forma de expropriação generalizada da vida: dos corpos, das subjetividades, dos rios, das florestas, montanhas, mares, solos, etc.

Não vivemos simplesmente uma pandemia. Padecemos de um projeto de sociedade que, ao alicerçar-se na destruição da natureza, na submissão de determinados grupos sociais e na capitalização generalizada da vida, cria as condições para a destruição do ecossistema necessário `a vida no planeta. Para Mbembe (2020), a modernidade foi, do princípio ao fim, uma interminável guerra travada contra os vivos.

Como ter uma vida respirável se aquilo a que nos acostumamos chamar, por força do capital e dos colonialismos, de progresso da civilização foi e ainda é construído sobre os escombros do ecossistema e de nós mesmos? Como criar estratégias coletivas de resistência se estas implicam em estar juntos, presentes, em contato entre os corpos? Em tempos de negação da vida, da diversidade e da democracia, são as políticas públicas - em suas diversas áreas - potencializadoras de resistências macro e micropolíticas?

Aqui, companheira, porque gostamos muito de história e porque consideramos que devemos historicizar as forças que atravessam o nosso tempo, pedimos licença para uma breve digressão a respeito das políticas públicas em nosso país. Antes, todavia, lembramos da advertência de Hobsbawm (2005, p. 14), quando este diz que: "os acontecimentos públicos são parte da textura de nossas vidas". Ao falarmos de políticas públicas, não se trata apenas de legislações, direitos, paradigmas e estratégias micro e macro políticas de intervenção no campo social. Trata-se, sobretudo, de "texturas" do viver.

\section{Políticas Públicas}

Segundo o Dicionário de Política, de Bobbio, Matteuci e Pasquino (1998, citado por Viana \& Baptista, 2012, políticas públicas são um composto de disposições e medidas que demonstram a orientação política do Estado e regulam as atividades governamentais, podendo variar com o tipo de economia, a visão sobre o papel do Estado e a atuação de grupos sociais. Tais políticas e serviços são um âmbito de disputa e transformação de significados, valores e orientações da sociedade, podendo agir sobre diferentes concepções e influenciar nas disputas de espaço, na luta ideológica (Fleury \& Ouverney, 2012). É de forma esperançosa que dizemos que elas, então, são influenciadas pelos valores sociais e, ao mesmo tempo, podem os afetar, em um processo dialético de assimilação e redefinição dos significados. Perguntamo-nos se temos nos mobilizado suficientemente para consolidar o papel de tais sistemas e políticas na criação de tensões e dissensos.

As políticas públicas brasileiras passaram a ganhar maior abrangência a partir da década de 70, já que anteriormente apenas contemplavam a população com emprego formal, associada à previdência. A partir de então, iniciou-se um longo processo em direção à universalização de tais políticas, que resultou, em 1988, com a Nova Constituição Federal, em um modelo de seguridade caracteristicamente nacional e universalizado (Pereira, n.d). Este processo baseou-se na ampla luta de movimentos sociais que, diante da crise na ditadura militar, contestaram o sistema anteriormente estabelecido, propondo novas reformas e modelos. É graças à resistência destes e de todos os que seguiram que hoje é possível afirmar a necessidade das políticas públicas e o dever do Estado na garantia de direitos (Fleury \& Ouverney, 2012).

O contexto sócio político exerce forte influência sobre as políticas públicas, em suas diversas facetas. Apesar das lutas e brechas construídas com suor e sangue, atualmente, com a disseminação das ideias neoliberais pelo Brasil, buscando "reduzir" a atuação do Estado e priorizar os interesses do mercado, o caos parece se instaurar cada vez mais. Nesse 
sentido, o que se passa, segundo Viana e Baptista (2012), é a restrição dos investimentos governamentais e, consequentemente, do acesso da população e das possibilidades encontradas pelos serviços.

Dessa maneira, a potencialidade dos mesmos é minada, com a implementação de um olhar meramente econômico que coloca as políticas como despesas a serem cortadas ${ }^{3}$. Mas, como nos lembra Lacerda (2015), essas críticas só se aplicam quando o dinheiro é desviado do Capital, já que, para serem usadas como amparo ao mesmo- no perdão de dívidas bancárias, por exemplo- as políticas passam a ser muito bem-vindas. $\mathrm{O}$ inanimado, companheira, segue pesando muito mais que a vida, em uma balança assassina e cruel. Esse contexto deixa suas marcas na atuação dos profissionais que precisam conviver com a precarização dos vínculos empregatícios, a cobrança por produtividade, a falta de investimento em qualificação, a ausência de materiais adequados e a desvalorização. Essas circunstâncias dificultam uma atuação implicada dos mesmos e naturalizam as situações dadas de sucateamento (Romagnoli, 2015).

Com a atual Reforma da Previdência, favorecendo as empresas com a desregulação das relações de trabalho (Teodoro, 2020), os constantes ensejos à privatização do nosso Sistema Único de Saúde e a Nota Técnica Nova Saúde Mental (11/20190) que flerta institucionalmente com a lógica manicomial, faz-se oferendas do dinheiro público às comunidades terapêuticas e desmantela-se grande parte das conquistas até então vigentes de cuidado com a saúde e com os Direitos Humanos. Enquanto isso, latejam leis que facilitam armas e agrotóxicos ${ }^{4}$.

Logo, torna-se explícito que o suposto afastamento técnico na elaboração e implementação das políticas é uma farsa muito

\footnotetext{
${ }^{3}$ Ressaltamos que este momento de pandemia se tornou propício para a intensificação da neoliberal. Como aponta Klein (2008), o “capitalismo de desastres" faz das crises oportunidades para majorar os processos do capital.
}

bem planejada. Os que se dizem neutros sempre tiveram lado: o seu compromisso com a agenda neoliberal e os seus interesses mercantis privatistas. Todo o processo é perpassado por disputas micro e macropolíticas, disputas essas que visam não apenas o campo das políticas públicas, mas também uma ideia de sociedade e sua organização econômica, política e social. Dessa maneira, o sistema neoliberal segue tornando o ar cada vez mais raro e as possibilidades de vida cada vez mais escassas. Em todos os sentidos.

Todavia, cara companheira, partindo do pressuposto que a macro e micropolítica coexistem indissociavelmente na produção de realidade (Rolnik, 1989), é possível dizer que, durante a formação e implementação de uma política pública, pode-se fazer surgir a expressão de intensidades e afetos. Logo, atuar de modo implicado nesses espaços é detectar os perigos e as potências envolvidas em cada um. Assim, por meio dessa atuação sensível é possível participar da formação de subjetividades e de outros mundos. É importante, portanto, considerar as narrativas desviantes ali produzidas, acerca dos próprios serviços e das concepções de sociedade, cidadania e direitos civis.

Seguindo o afirmado por Jacques (2012), o que tem se dado na contemporaneidade é a homogeneização das subjetividades e desejos, eliminando conflitos, mediações qualitativas e impondo uma paz forçada. Esse processo mina a existência de diversas e diferentes experiências, capturandoas e domesticando-as. Isso pode ocasionar uma dificuldade em criar narrativas que possibilitem a troca coletiva dos caminhos desviantes existentes. Porém, tais caminhos continuam a existir. Sendo assim, mesmo com a violência da materialidade e a existência de práticas de silenciamento de narrativas resistentes, existem possibilidades de se deslocar.

\footnotetext{
${ }^{4}$ De acordo com a ONG Repórter Brasil (Grigori, 2021), 118 agrotóxicos foram liberados para o uso no Brasil durante a pandemia.
} 
A atuação nas políticas públicas pode, pelas brechas encontradas, cumprir esse papel, enfatizando questões da experiência, do corpo e da alteridade na cidade. Mesmo nas circunstâncias de sucateamento impostas propositalmente, é possível haver atos clandestinos, ainda que estes sejam frágeis. Em uma atuação territorializada e implicada há grande potência de experienciar e narrar a vivência das diferenças, tendo novas trocas e agindo com microrresistências que causam dissenso. Ela pode, assim, ocasionar, intencionalmente, em si e no outro, um novo tipo de pensamento e ação acerca de várias questões, promovendo uma troca de narrativas. Ademais, com a vivência do território, é possível compartilhar perspectivas ali apreendidas, como outras visões e narrativas acerca do mundo que nos envolve.

Tais atuações erráticas, a partir de noções diferentes de cidadania, resistência e comunidade, podem, portanto, ser usadas como ferramentas singulares que afastam o conforto do familiar e atraem o estranhamento e a alteridade. Assim, apesar de todas as circunstâncias, é possível resistir pelas brechas e sobreviver compartilhando narrativas desviantes. Para tanto, é necessário conhecer os territórios e os meios pelos quais eles produzem sentido e significado, inventando seu cotidiano e modos de resistir. Ademais, é importante se colocar enquanto aliado, tendo consciência que o ideal é que essa atuação não seja mais necessária, mas, que, enquanto for, o melhor é ocupar esse espaço de poder dentro das políticas de forma estratégica, a partir das brechas que surgirem.

Por fim, é importante lembrar sempre que tais brechas, apesar de potentes, ainda são brechas, para que não se deixe de lutar por um mundo onde não seja preciso desviar tanto para alcançar o mínimo. Assim, como nos lembra Lacerda (2015), as políticas podem ser uma face de contestação ao que está posto, mas enfrentam apenas refrações da questão social. Se queremos encontrar saídas, experimentar outros modos de viver, precisamos seguir adiante, ousar, ter consciência das concessões feitas e seguir na luta por uma mudança econômica estrutural que vá além da humanização de uma vida inerentemente desumanizante. Precisamos reconhecer que a mera atuação profissional não é suficiente, que é necessário agir e estabelecer alianças com movimentos sociais e anticapitalistas.

\section{Corpos em risco}

Companheira, apesar de pensar nas políticas públicas como potência de transformação, não podemos deixar de questionar: quando foi que para os povos latino-americanos os seus corpos não estavam em risco? Quando foi que para a nossa gente pobre suas vidas não se tornaram descartáveis? Nossa história é feita de confinamentos e massacres: Canudos, Eldorado dos Carajás, Candelária, praça da Sé, Vigário Geral, Complexo do Alemão. A lista é infindável. Temos a quarta maior população carcerária do mundo. Há álcool em gel e máscaras para os privados de liberdade que se amontoam em celas superlotadas? A política nacional de saúde para os privados de liberdade funciona? Ela foi efetivada? A população em situação de rua: quantos foram contaminados com a Covid19? Quantos estão contaminados? Não existem dados para este público.

Chamamos de corpos em risco as vidas que se tornam descartáveis (Alvarenga Filho, 2013), alvos que são de exercícios de poder que promovem sua repressão e buscam o seu aniquilamento. Nos referimos a trabalhadores sem terra, sem teto; população em situação de rua; privados de liberdade; populações de territórios periféricos, como favelas; povos da floresta, dentre outros. O risco que estes corpos, estas vidas, correm é a de serem exterminados devido a repressão às lutas dos movimentos sociais por terra e moradia, devido às políticas de higienização urbana, devido aos conflitos entre forças de segurança do Estado e o varejo do tráfico de drogas, devido a destruição da natureza. Enfim, devido a negação da humanidade destes corpos. A linha abissal que divide o mundo os coloca na posição daqueles que devem morrer para que supostamente outros possam viver. 
Como você bem sabe, companheira, a Organização Mundial da Saúde- OMSdeclarou, em 11 de março de 2020, que estávamos em estado de emergência de saúde pública, por conta da infecção em massa da doença Covid-19 ou, mais popularmente conhecido, o coronavírus. A pandemia carrega consigo centenas de corpos, todos os dias, pela doença, pela exacerbação do empobrecimento dos que já eram pobres, pela fome, pela "ineficácia" 5 " do governo e pelo sucateamento da saúde pública. Contudo, como se todo o mal ainda não fosse suficiente, o vírus intensificou também variadas formas de sofrimento psíquico que assola os brasileiros.

O isolamento social é um fator de extrema necessidade que auxilia no rastreamento, feito pelas autoridades de saúde, da circulação do vírus e no tratamento mais eficaz e rápido dos pacientes, evitando novos contágios. Recentemente, no mês de março, completou-se um ano que alguns brasileiros (as) que possuem o privilégio socioeconômico de conseguir seguir a recomendação da OMS vivem dessa forma. Entre idas e vindas de ondas vermelhas e roxas $^{6}$ nesse oceano que parece querer nos engolir, muitos são os afetos de tristeza fazendo emergir e potencializando "linhas de insalubridade"." Devido às circunstâncias pandêmicas e seus desdobramentos sociais, a saúde mental de muitos (as) afundou-se em desesperança de que dias ensolarados, e acompanhados de quem se ama, virão.

Há ainda de se lembrar daqueles (as) que, mesmo com medo por si e pelos seus, precisam continuar trabalhando. E o medo contínuo pode se transformar em pavor, ansiedade e fobia. Além disso, quando incluímos a perspectiva de gênero nas discussões sobre saúde mental na pandemia, o caso de mulheres isoladas com seus maridos abusivos, presas em suas próprias casas e

\footnotetext{
${ }^{5}$ Se compreendemos que, dentro da sociedade neoliberal, a crise é um projeto que serve aos interesses de majoração do capital, muitos têm sido os governos - a nível federal, estadual e municipal - cuja suposta "ineficácia" política tem auxiliado a ampliação do sucateamento e privatização do Estado.
}

presas de quem elas julgavam parceiros, precisa ser lembrado. Companheira, não se deve deixar de pensar, também, em como está a saúde mental daqueles que têm fome, frio, sede, dor e depositavam as poucas esperanças que tinham naqueles que encontravam pelas ruas e que, agora, não encontram mais, sendo necessário a consideração das necessidades psicossociais e das situações de maior vulnerabilidade, como cita a cartilha "Saúde Mental e Atenção Psicossocial na Pandemia Covid-19" da Fundação Fiocruz (Melo et al., 2020). Há, ainda, a necessidade de pensar sobre quem já é esquecido e repudiado pelo governo, como os negros, indígenas, população lgbtqia + , pcd's e famílias em situação de pobreza. Estes, em função da violência estrutural e desigualdade social que atravessam nosso país, estão muito mais expostos ao adoecimento e à violência (Melo et al., 2020). Por isso, agora padecem, um pouco mais a cada dia, com medo do amanhã que virá. Se é que virá, como alertou Drummond de Andrade (2002).

A pandemia escancarou todas as insuficiências do Sistema Único de Assistência Social- SUAS - , decorrentes do longo processo de sucateamento feito nas políticas públicas. Relatos de trabalhadores das áreas sociais demonstram equipes desfalcadas e números insuficientes de Centros de Referência da Assistência Social-CRAS- e Centros Especializados de Referência de Assistência Social-CREAS - , se comparados à extensa população que necessita ser atendida. Além disso, os contratos de trabalho estão precarizados e há a ausência de uma política sólida que valorize as instâncias sociais. Uma nota $^{8}$ de repúdio expendida pelo Conselho Federal de Serviço Social- CFESS - no dia 10 de dezembro de 2020, argumentou contra os desmontes feitos na área social, por parte do governo federal, que reforçam a ineficiência governamental em propor ações efetivas para o

\footnotetext{
6 Nos referimos às nomenclaturas utilizadas pelo Governo do Estado de Minas Gerais.

${ }^{7}$ Termo utilizado por Luiz Fuganti em uma aula do curso de "Formação em Esquizoanálise". $\begin{array}{llll}8 & \text { Nota em: } \\ \text { http://www.cfess.org.br/visualizar/noticia/cod/1772 }\end{array}$
} 
enfrentamento do Coronavírus e das questões de saúde mental agravadas pelo contexto social na pandemia.

Alguns exemplos de tal desmonte, que a nota do Conselho Federal de Serviço SocialCFESS - mostrou, foi a pretensão do governo federal em implementar a retirada dos atendimentos psiquiátricos dos Centros de Atenção Psicossocial- CAPS—, além de revogar a política de atenção à saúde mental da população indígena e transferir o financiamento e a regulação das "unidades de acolhimento" para o Ministério da Cidadania, retirando, assim, tal instância do âmbito da Saúde. É notório que o atual governo, na contramão das orientações da ciência e das práticas bemsucedidas realizadas pela saúde pública brasileira, acelera e intensifica os ataques às políticas de saúde mental, o que há muito já vêm ocorrendo em solo brasileiro.

Os poderosos seguem, a cada dia, mais poderosos e os miseráveis seguem morrendo da mesma morte severina, como afirmou João Cabral de Melo Neto, de velhice antes dos trinta, de emboscada antes dos vinte, de fome um pouco por dia e atualmente, também, de pandemia (Melo Neto, 2007). E, alheios ao sangue escuro que encharca as ruas brasileiras, as autoridades governamentais seguem contribuindo com o caos. Um exemplo disso é o sucateamento do Sistema Único de SaúdeSUS - materializado pela lei 8080 de 1990que é orientado por uma concepção ampla do direito à saúde e do papel do Estado, tendo diretrizes válidas para todo o território nacional. (Noronha, Lima e Machado, 2012). Esse sistema, a partir de sua descentralidade e capilaridade, possibilita o alcance a diferentes regiões e contextos, levando noções ampliadas de saúde e favorecendo grande articulação no território nacional. Dessa forma, durante a pandemia, não foi necessário que construíssemos uma nova estrutura, como ocorreu em outros países. Afinal, o Brasil já contava com um sistema único, público e gratuito. Contudo, apesar de ser central no combate à pandemia, tal organização segue recebendo ataques consecutivos do atual governo anticientífico, negacionista e neoliberal, por meio, principalmente, de desinvestimentos.

Do meio desse apocalíptico cenário, entre trocas de ministros e manutenção de uma apologia ao "homem endividado" que precisa expiar a si mesmo, desvela-se o "modo de predação" sustentado pela cultura da crise (Lazzarato, 2017), que tem como resultado um crescimento exponencial do abismo entre ricos e pobres no Brasil. Enquanto isso, seguimos atrasados na fila de vacinação de um Plano de imunização da população que anda a passos arrastados. A pandemia escancarou essa subjugação de corpos que, já antes vulneráveis, se tornaram ainda mais vulnerabilizados. Assim, o Estado segue com políticas de exclusão que elegem os grupos considerados úteis ou descartáveis (Achille Mbembe, 2011 citado por Santos et al., 2020). Essa concepção que cria noções da existência de humanos e sub-humanos faz parte de uma iniciativa necropolítica, perceptível por meio da distribuição diferencial de direito à vida realizada pelo Estado (Brito, 2018 citado por Santos et al., 2020). E, assim, fazem-se mercenários da morte, seja ela física ou mental, dos povos que aqui vivem e até, citando novamente João Cabral de Melo Neto, de gente não nascida.

\section{Para (não) concluir}

Minha cara, gostaria eu de poder segredar-lhe ventos de boas novas, mas sentimos que os ares trazem imagens de um outono onde caem folhas e Vidas Secas, pintadas com o sangue rubro do povo preto, pobre e analfabeto. Desnudadas de seu fino manto de políticas assistenciais, marcado pela "fragilidade de um sistema em processo de desmonte" (Oliveira et al., 2020, p. 6), veem-se estes entregue à sorte dos urubus neoliberais que dilaceram o coração das políticas públicas em saúde que já vinha pulsando cansado dos constantes desmontes e desmanches das forças políticas que se instauraram. A Covid-19 anda comendo mais pelas beiradas.

Lembramos de um passado um tanto quanto presente de um medo que se instaurou 
desse invisível e microscópico (des)habitante. Se bem que paradoxalmente de uma invisível mão (Smith, 2002) já estávamos empestiados desde os últimos altos democráticos, uma mão que vem desarticulando espaços e rearticulando arranjos em prol de uma projeto econômicopolítico que não permite respirar.

Companheira, apesar de nossas palavras duras e das críticas necessárias, nem tudo está dominado. Sabemos que é sempre muito mais fácil cairmos no coro dos fatalistas, dos dominados por afetos de tristeza, que diante das mazelas do viver, são capazes apenas de reafirmar o mais do mesmo da lamúria e do queixume. Uma passagem de Conceição Evaristo nos faz lembrar Foucault e a sua concepção de poder: sendo o poder embate de forças, onde há poder, haverá resistências. Pois, as correlações de poder se dão em um campo complexo e múltiplo de embates e enfrentamentos na microfísica do cotidiano. Para Evaristo (2018), "por mais que uma voz hegemônica queira comandar, a água escapole entre os dedos. Você não segura. Não retém a força da água. Então o povo encontra maneiras de se afirmar, de falar, de dizer".

\section{Referências}

Alvarenga Filho, J. R. (2016). A "Chacina do Pan" e a produção de vidas descartáveis. Fractal: Revista de Psicologia, 28(1), 111-117. Recuperado de https://periodicos.uff.br/fractal/article/view/ $\underline{5103}$

Andrade, C. D. (2002). Brejo das Almas. Poesia completa. Rio de Janeiro: Nova Aguilar.

Evaristo, C. (2018). É preciso questionarmos as regras que me fizeram ser reconhecida apenas aos 71 anos. $B B C$ News Brasil. Recuperado de https://www.bbc.com/portuguese/brasil43324948

Fleury, S., \& Ouverney, A. M. (2012). Política de Saúde: uma política social. In L. Giovanella, S. Escorel, L. V. C. Lobato, J. C. Noronha, A. I. Carvalho (Orgs.), Políticas e Sistemas de Saúde no Brasil (pp. 25-57). Rio de Janeiro, RJ: Editora Fiocruz.

Foucault, M. (1985). História da sexualidade: a vontade de saber. Rio de Janeiro, Brasil: Graal.

Foucault, M. (2014). Vigiar e punir. Petrópolis, Rio de Janeiro.

Galeano, E. (2012). Os filhos dos dias. Porto Alegre, Brasil: LP\& M.

Grigori, P. (2021). 118 agrotóxicos são aprovados durante a pandemia, liberação e "serviço essencial". Repórter Brasil. Recuperado de https://reporterbrasil.org.br/2020/05/96- agrotoxicos-sao-aprovados-durante-apandemia-liberacao-e-servico-essencial/

Han, B. (2017). Sociedade do cansaço. Petrópolis, Rio de Janeiro: Vozes.

Hobsbawm, E. (2005). O breve século XX: a era dos extremos. São Paulo, Brasil: Companhia das Letras.

Jacques, P. B. (2012). Prólogo. In P. B. Jacques (Ed.), Elogio aos errantes (pp. 1124). Salvador, BA: EDUFBA.

Lacerda, F. (2015). Podem as políticas públicas emancipar? In D. C. Antunes, M. G. A. Calegare, A. F. Lima (Orgs.), A Psicologia Social e os atuais desafios éticopolíticos no Brasil (pp. 111-126). Porto Alegre: ABRAPSO. Recuperado de: https://www.abrapso.org.br/conteudo/view? ID CONTEUDO=1177

Lazzarato, M. (2017). O governo do homem endividado. São Paulo, SP: N-1 Edições.

Lipovetsky, G., Serroy, J. (2015). A estetização do mundo: viver na era do capitalismo artista. São Paulo, Brasil: Companhia das Letras.

Klein, N. (2008). A doutrina de choque: a ascensão do capitalismo do desastre. Rio de Janeiro, Brasil: Nova Fronteira.

Krenak, A. (2019). Ideias para adiar o fim do mundo. São Paulo, Brasil: Companhia das letras.

Krenak, A. (2020a). O amanhã não está à venda. São Paulo, Brasil: Companhia das letras. 
Krenak, A. (2020b). A vida não é útil. São Paulo, Brasil: Companhia das letras.

Mbembe, A. (2020). O direito universal à respiração. AOC media - Analyse Opinion Critique. Recuperado de https://www.buala.org/pt/mukanda/odireito-universal-a-respiracao

Melo, B. D., Lima, C. C., Moraes C. L., Andrade, C. B., Pereira, D. R., Souza, E. R., Ribeiro, F. M. L., ... Rabelo, I. V. M. (2020) Saúde mental e atenção psicossocial na pandemia COVID-19: violência doméstica e familiar na COVID-19. Rio de Janeiro: Fiocruz, 2020. Recuperado de https://portal.fiocruz.br/documento/saudemental-e-atencao-psicossocial-violenciadomestica-e-familiar-na-pandemia-decovid-19

Neto, J. C. M. (2007). Morte e vida severina e outros poemas. Rio de Janeiro: Alfaguara.

Noronha, J. C., Lima, L. D., \& Machado, C. V. (2012). O Sistema Único de SaúdeSUS. In L. Giovanella, S. Escorel, L. V. C. Lobato, J. C. Noronha, A. I. Carvalho (Orgs.), Políticas e Sistemas de Saúde no Brasil (pp. 365-393). Rio de Janeiro, RJ: Editora Fiocruz.

Oliveira, R. G. de, Cunha, A. P. da, Gadelha, A. G. dos S., Carpio, C. G., Oliveira, R. B. de, \& Corrêa, R. M. (2020). Desigualdades raciais e a morte como horizonte: considerações sobre a COVID-19 e o racismo estrutural. Cadernos de Saúde Pública, 36(9). doi: 10.1590/0102$311 \times 00150120$

Pereira, L. (n.d.). Políticas Públicas de Assistência Social brasileira: avanços, limites e desafios. Recuperado de: http://www.cpihts.com/PDF02/Larissa\%20 Dahmer\%20Pereira.pdf

Preciado, P. (2018). Lá izquierda bajo la piel. Um prólogo para Suely Rolnik. In S. Rolnik (Ed.), Esferas da insurreição: notas para uma vida não cafetinada. São Paulo, Brasil: N-1 Edições.
Rolnik, S. (1989). Cartografia Sentimental, Transformações contemporâneas do desejo. São Paulo, SP: Editora Estação Liberdade.

Romagnoli, R. C. (2015). Apontamentos metodológicos da pesquisa-intervenção no contexto da assistência social: conexões entre universidade e equipe. Revista Pesquisas E Práticas Psicossociais, 10(1), 129-139. Recuperado de http://www.seer.ufsj.edu.br/index.php/revis ta ppp/article/view/Romagnoli

Santos, B. S. (2007). Para além do pensamento abissal: das linhas globais a uma ecologia de saberes. Novos Estudos - CEBRAP, (79), 71-94. doi: 10.1590/s010133002007000300004

Santos, H. L. P. C., Maciel, F. B. M., Santos, K. R., Conceição, C. D. V. S., Oliveira, R. S., Silva, N. R. F., \& Prado, N. M. B. L. (2020). Necropolítica e reflexões acerca da população negra no contexto da pandemia da COVID-19 no Brasil: uma revisão bibliográfica. Ciência \& Saúde Coletiva, 25(suppl 2), 4211-4224. doi: 10.1590/1413-812320202510.2.25482020

Saramago, J. (1995). Ensaio sobre a cegueira. São Paulo, Brasil: Companhia das Letras.

Smith, A. (2002). Teoria dos Sentimentos Morais. São Paulo, SP: Martins Fontes.

Teodoro, L. C. A. (2020). A Onda Neoliberal no Brasil e o Desmonte das Políticas Públicas: análise das reformas trabalhistas e da previdência. Serviço Social Em Perspectiva, 4(Especial), 792-805. Recuperado de https://www.periodicos.unimontes.br/index. $\mathrm{php} /$ sesoperspectiva/article/view/1518

Viana, A. L. A., \& Baptista, T. W. F. (2012). Análise de Políticas de Saúde. In L. Giovanella, S. Escorel, L. V. C. Lobato, J. C. Noronha, A. I. Carvalho (Orgs.), Políticas e Sistemas de Saúde no Brasil (pp. 59-87). Rio de Janeiro, RJ: Editora Fiocruz. 


\section{Dados sobre as autoras:}

- José Rodrigues de Alvarenga Filho: Doutor em Psicologia (UFF). Professor Adjunto do Departamento de Psicologia da Universidade Federal de São João Del Rei (UFSJ) e da Pósgraduação Interdisciplinar em Artes, Urbanidades e Sustentabilidade (PIPAUS).

- Clara da Mata Anselmé: Acadêmica de Psicologia pela Universidade Federal de São João Del Rei (UFSJ). Possui pesquisa na área de Psicologia Social.

- Heitor Soares Sanglard: Acadêmico de Psicologia pela Universidade Federal de São João Del Rei (UFSJ). Possui pesquisas na área de Psicologia Social e Psicanálise.

- Izabella Dias Lombardi: Acadêmica de Psicologia pela Universidade Federal de São João Del Rei (UFSJ). Possui pesquisa na área de Psicologia Social.

Declaração de Direito Autoral

A submissão de originais para este periódico implica na transferência, pelos autores, dos direitos de publicação impressa e digital. Os direitos autorais para os artigos publicados são do autor, com direitos do periódico sobre a primeira publicação. Os autores somente poderão utilizar os mesmos resultados em outras publicações indicando claramente este periódico como o meio da publicação original. Em virtude de sermos um periódico de acesso aberto, permite-se o uso gratuito dos artigos em aplicações educacionais e científicas desde que citada a fonte conforme a licença CC-BY da Creative Commons. 